\title{
Research on Energy Management Strategy of Connecting and Off-grid Charging Station with Photovoltaic and Storage System
}

\author{
Xiao-Yu ZHANG ${ }^{1, a}$, Shou-Xin GU ${ }^{2, b,{ }^{*}}$ \\ ${ }^{1}$ North China Electric Power University, Baoding 071003, Hebei, China. \\ azhangxiaoyuncepu@126.com, bshanguxin@163.com \\ *Xiao-Yu ZHANG
}

\begin{abstract}
Keywords: Connecting and off-grid, Energy management, Electric vehicle charging station, Inverter control
\end{abstract}

Abstract. With the rapid development of PV charging station with storage system, due to the inadequate utilization of solar energy in traditional off-gird charging stations and grid-connected charging stations, this paper present a novel connecting and off-grid PV charging station with storage system, which with stable structure, and good scalability, and ability to take full advantage of solar energy. Then we analyzed the grid-connected inverter's control strategy in detail, and because of the inverter's limited capacity with nonlinear load when the station was off-grid, this paper proposed an improved control method by adding output current feedback loop. In order to make full use of PV energy, an energy management strategy had been proposed in this work based on the light intensity to divide the charging station operation into four kinds of modes. Simulation tests, conducted in Matlab/Simulink, about the switching between the four conditions demonstrate the validity of energy management strategies.

\section{Introduction}

According as the decreasing of fossil energy and environment problem increasingly prominent, the development of green energy is imminent [1-2]. The increasing traditional automobiles has become one of the main reasons of the environment pollution in urban, and that's why the Chinese government has been trying to speed up the development of electric vehicles. The development of electric vehicles is one of the most effective ways to solve the problem of environment pollution in cities, but also play a key role for the efficient use of energy [3]. Charging station, which is the essential way charging for the electric vehicles, has become a topic of current research, and adopting new energy such as solar in electric vehicle charging stations must become the mainstream in the future.

The off-grid charging station with PV and storage system and the connecting grid charging stations with PV and storage system were contrasted in [4], in which the advantages and disadvantages and the flow of the energy of the above two types of charging station have been analyzed. The maximum power point tracking (MPPT) control method of the PV array is introduced in [5]. The inverter's control methods have been studied in [6 7] when charging station is connecting grid or off grid. The bidirectional DC/DC circuit and the charge/ discharge control method of battery is introduced in [8].

On account of traditional charging stations' defects, this paper proposed a new structure, connecting and off-grid charging station with PV and storage system. The control strategy of the inverter has been analyzed and studied in this paper whenever the charging station is connected or off the grid, and the energy management strategy has been proposed based on light intensity in order to make full use of PV energy. Finally, the scheme is demonstrated to be reasonable in Matlab/Simulink.

\section{Charging Station Scheme}

Traditional charging station is divided into two types: connecting grid charging station and off-grid charging station, and the structure of the above two kinds of station is illustrated in figurel and figure 2 respectively [9]. Each of the above two kinds of traditional charging stations has its own 
shortcomings. When the load power is small and battery charged higher status, the photovoltaic cells cannot to maximum power output, and the off-grid charging station with PV and storage system cannot make full use of PV energy. When the power grid failure, the grid-connected charging station will be collapsed at one heels, and the PV energy would be squandered.

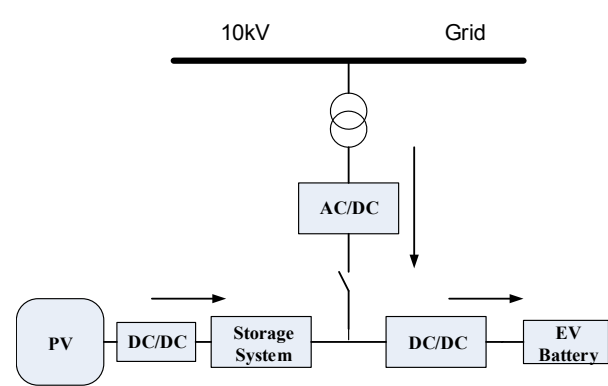

Fig. 1. Structure of Off-grid Charging Station with PV and Storage System

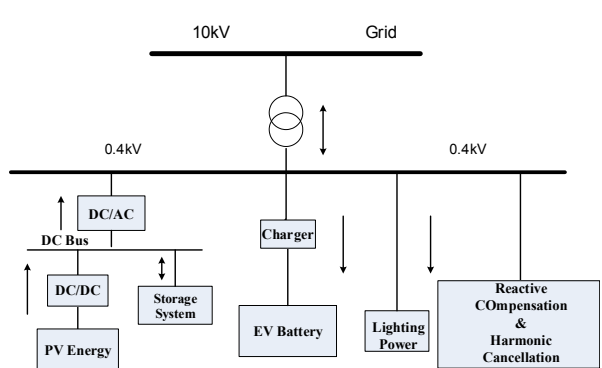

Fig. 2. Structure of Grid-connected Charging Station with PV and Storage System

Combined with the advantages of the traditional charging stations, this paper proposed the connecting and off-grid charging scheme with PV and storage system, with the structure shown in figure 3.

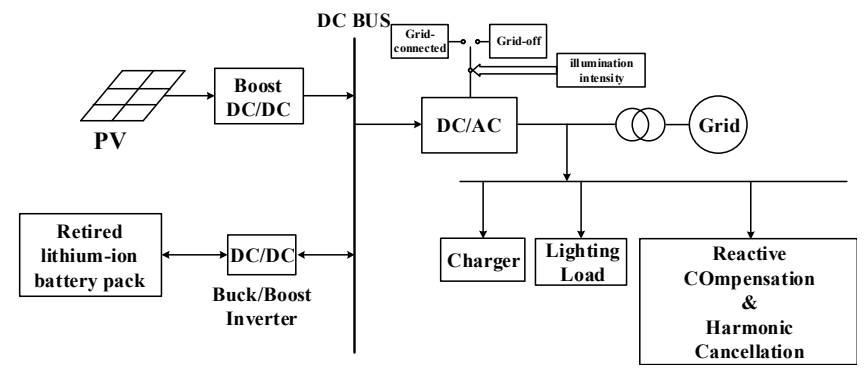

Fig. 3. Structure of Connecting and Off-grid Charging Station with PV and Storage System

Electric energy would not only be supplied to load and grid by the PV system, but also flow from grid to load when the charging station is grid-connected. Electric energy would be supplied to load by the PV and battery energy storage system when the charging station is off-grid. The charging station with PV and storage system, proposed by this paper, is composed of photovoltaic module, battery energy storage system, connecting and off-grid mode selection module, inverter control module and power management strategy module.

\section{Control Strategy of PV Charging Station with Storage System}

\subsection{MPPT control strategy.}

Photovoltaic Maximum Power Tracking Technology (MPPT) can realize the Maximum use of photovoltaic power, and the methods commonly used at present are disturbance observation method, the constant voltage method and the incremental conductance method, etc. [10]. We use the incremental conductance method in this paper to track the maximum power of PV system. The P-V curve of solar cell shows that the maximum power point meets $d P / d U=0$, and on the left side of the maximum power point meets $d P / d U>0$, and on the right side of maximum power point meets $d P / d U$ $<0$, then we can find the maximum power point voltage by set up the appropriate search step length.

\subsection{Bidirectional DC/DC Control Strategy.}

Buck/Boost circuit has been used on bi-directional DC/DC converter, as its topology structure shown in figure 4. 


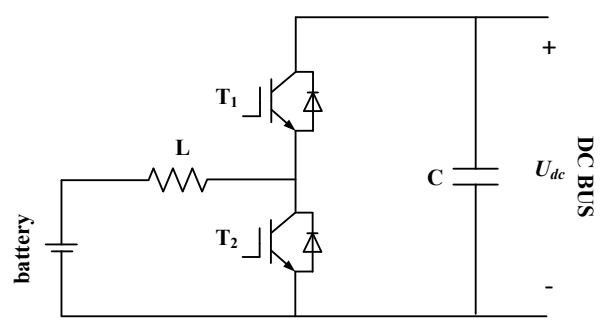

Fig. 4. The Bidirectional DC/DC Converter Topology Structure

There are a lot of control strategies of the DC/DC converter, the voltage outter loop current inner loop control strategy and the power outter loop current inner loop control strategy are some of the typical strategies, and the two kinds of control mode has its own advantages and disadvantages:

Based on the PV power and the feedback information from dc bus, method of power outter loop current inner loop can precisely control the output power of lithium-ion batteries, and rapidly remedy power balance, and stabilize output power. Lithium battery, with small voltage ripple and small current ripple, responses quickly, however, it cannot directly control the dc bus voltage, and if we aim to make dc bus voltage stability within $\pm 10 \mathrm{~V}$, large capacitor on dc bus is necessary.

Method of voltage outter loop current inner loop has the advantage of controlling dc bus voltage directly, and the output power of lithium-ion batteries would be controlled indirectly, moreover, the capacitor on dc bus is smaller, however, the output power、voltage ripple and current ripple would be larger.

In order to stabilize the dc bus voltage, this paper adopt the method of voltage outter loop current inner loop.

\subsection{Inverter Control Strategy.}

DC bus of the charging station connects grid by voltage-type inverter, as its topology shown in figure 5 .

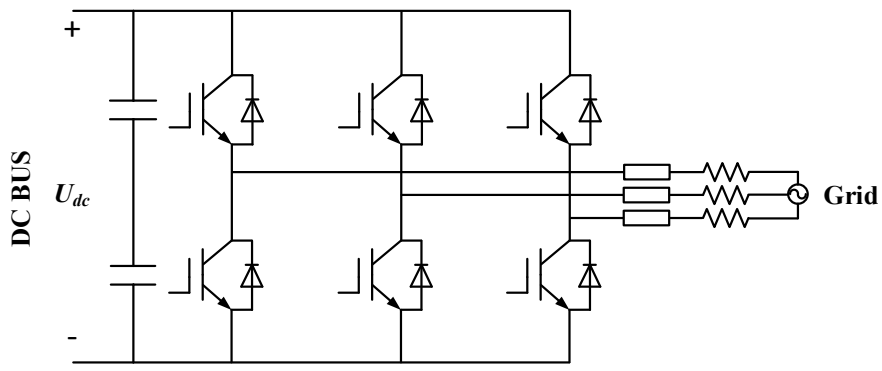

Fig. 5. Three-phase voltage-type grid-connected inverter topology structure

The control strategy of DC/AC inverter is divided into two communicarions: grid-connected method and off-grid method because of the two operations of the charging station.

When the PV charging station with storage system is connecting grid, PQ control method is one of the most used in various control methods of inverter. The control of active power and reactive power are decoupled in PQ control method, and if some input signals and reference signals would be changed, another control method with another constant be the reference signal would be obtained. The following three PQ control deformation modes are the most common: DC voltage constant and reactive power constant control、 inverter output voltage control and the simplified power constant control [11]. Control method of grid-connected inverter in this paper is dc voltage constant and reactive power constant control, and the control model structure, built on Matlab/Simulink platform is shown in figure 6. 


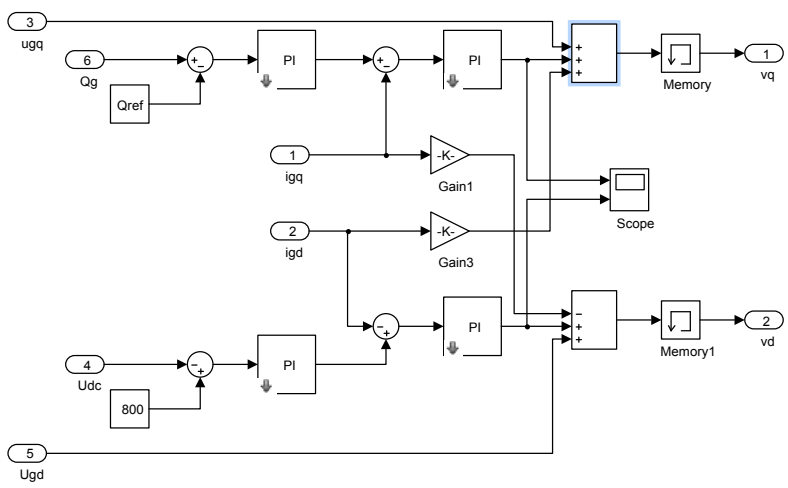

Fig. 6. The control model structure of grid-connected inverter when the charging station is grid-connected

The inverter is equivalent to a voltage source when the PV charging station is off-grid. When the inverter output voltage is stable, load can operate with high efficient and strong stability, and that's why the control of inverter output voltage is necessary. However, current inner loop must be introduced because some factors, such as current anti-jamming , capacity with nonlinear load, etc. must be considered in designing inverter power supply[12].

Inner loop sampled current value is filtering inductance current or filtering capacitance current. Nevertheless, capacitances' characteristics result in the voltage phase lag in the current phase, and the current can react the changing trend of output voltage to some extent, however, it couldn't reflects its own value. Yet the inductance current does not exist this kind of problem [13]. In conclusion, the inductance current inner loop and voltage outer loop control method is adopted in this paper, and the structure of control model simulation is illustrated in figure 7.

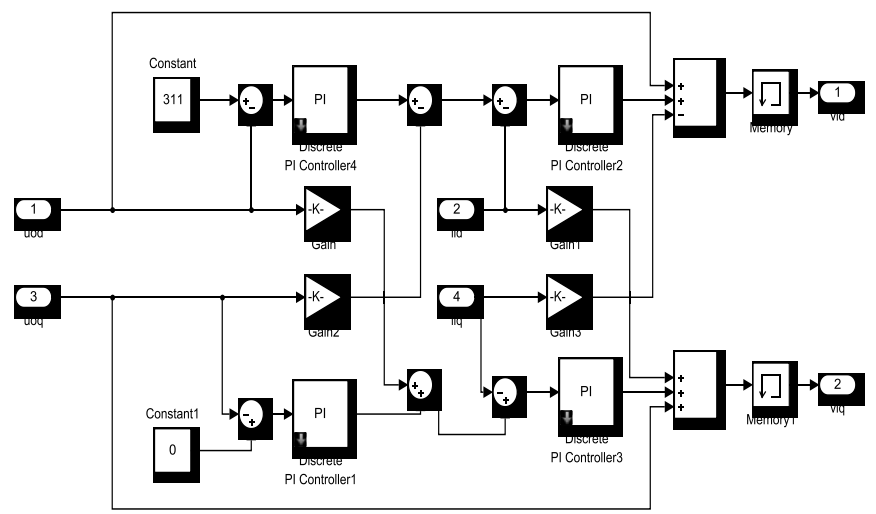

Fig. 7. The control model structure of grid-connected inverter when the charging station is off-grid

\section{Energy Management Strategy of PV Charging Station with Storage System}

In order to realize the PV charging station's stable operation and make the best use of energy, a relatively perfect energy management strategy must be developed on the basis of the running state of PV module, retired battery energy storage module, power grid and load state to balance power[14]. This paper presents a new energy management strategy according to the different light intensity during a day for make full use of PV energy.In this paper, the operation strategy of PV charging station with storage system is divided into two kinds of modes: grid-connected and off-grid, and the power balance is described as follows:

$$
\begin{aligned}
& P_{p v}+P_{\text {bat }}+P_{\text {grid }}=P_{\text {load }} . \\
& P_{p v}+P_{\text {bat }}=P_{\text {load }} .
\end{aligned}
$$


where $P_{\mathrm{pv}}$ is $\mathrm{PV}$ power, $P_{b a t}$ is storage battery power, $P_{\text {grid }}$ denotes the power from or to the grid, and $P_{\text {load }}$ is the power required by the load.

The operation mode of PV charging station with storage system switching according to the different light intensity to improve the economy and environmental protection. This paper divided the working modes of PV connecting and off-grid charging station with storage system into the following four:

Mode 1: If the PV array is under a serious shortage of light, to make energy storage system capacity in its limits, and to prevent from the battery's life span reduced due to excessive charging and discharging, the charging station would be grid-connected, and the electrical energy, load required, would be provided by the energy storage system and grid. In such a condition, $P \mathrm{PV} \approx 0$, grid-connected inverter would work in the grid-connected model, and the energy storage system bi-directional DC/DC converter would work under the Boost mode to stabilize the DC bus voltage around 800V.

Mode 2: If the light irradiation on the PV array is weak, the PV power could not fully meet the load demand, so the electrical energy, load required, would be provided by the energy storage system and $\mathrm{PV}$, and the charging station would be off-grid. Under the circumstances, $P_{\mathrm{pv}}+P_{\mathrm{bat}}=P_{\text {load, }}$ grid-connected inverter would work in the off-grid model, and the energy storage system bi-directional DC/DC converter would work under the Boost mode to stabilize the DC bus voltage around $800 \mathrm{~V}$.

Mode 3: If the sunlight is strong, the load power would be offered by PV system, and excess electrical energy would be stored in the battery energy storage system, and the charging station would still run away from the grid. On this occasion, $P_{\mathrm{pv}}=P_{\text {bat }}+P_{\text {load, }}$, the grid-connected inverter would be off-grid, and the energy storage system bi-directional DC/DC converter would work under the Buck mode to charge the battery and stabilize the DC bus voltage around $800 \mathrm{~V}$.

Mode 4: When the sunlight is too strong, the electric energy, desired by the load and storage system, will be satisfied by PV array, and the excess power will be send to grid, and the charging station will be grid-connected. In such a condition, the grid-connected inverter would be off-grid, and if the DC bus voltage $U_{\mathrm{dc}}>800 \mathrm{~V}$, the bi-directional $\mathrm{DC} / \mathrm{DC}$ converter would work in Buck mode to charge the battery, and if the DC bus voltage $U_{\mathrm{dc}}<800 \mathrm{~V}$, the bi-directional DC/DC converter would work in Boost mode to discharge the battery. The four kinds of operation modes of the charging station are illustrated in figure 8 (a), (b), (c), (d) respectively.

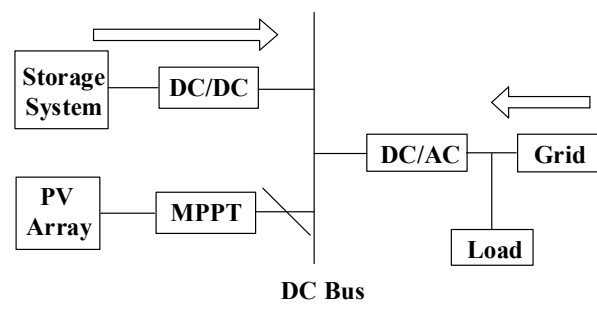

(a) Mode 1

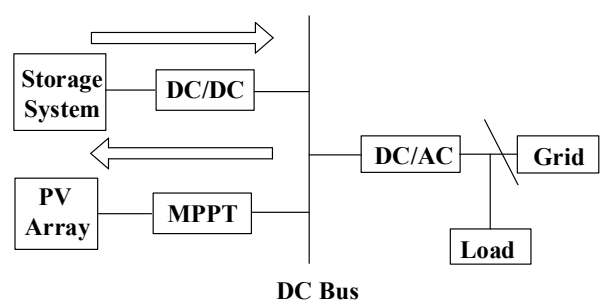

(c) Mode 3

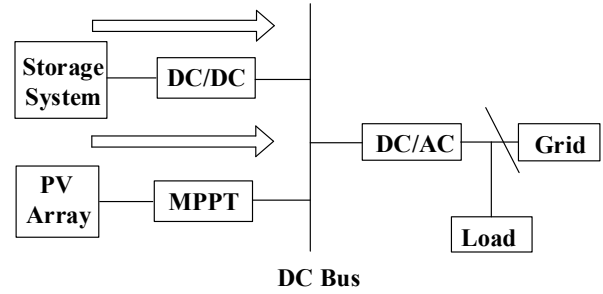

(b) Mode 2

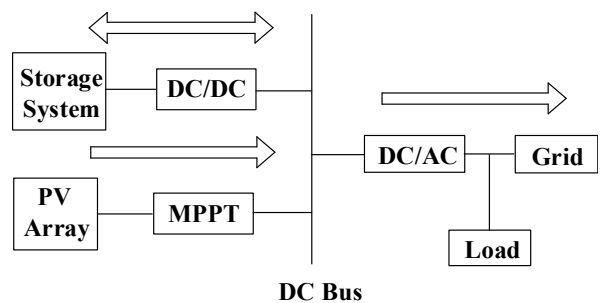

(d) Mode 4

Fig. 8. The charging station operation modes 


\section{Simulation Verification}

The simulation of connecting and off-grid PV charging station with storage system is built on the Matlab/Simulink platform, and the parameters of the photovoltaic cells are as follows: $T_{\text {ref }}=25^{\circ} \mathrm{C}$, $S_{\mathrm{ref}}=1000 \mathrm{~W} / \mathrm{m}^{2}, U_{\mathrm{oc}}=400 \mathrm{~V}, I_{\mathrm{sc}}=320 \mathrm{~A}, U_{\mathrm{m}}=360 \mathrm{~V}, I_{\mathrm{m}}=300 \mathrm{~A}$; Parameters of bi-directional DC $/ \mathrm{DC}$ converter: $L=4.5 \mathrm{mH}, C=1200 \mathrm{uF}$; Dc bus voltage $U_{\mathrm{dc}}=800 \mathrm{~V}, C=5 \mathrm{mF}$. The nominal capacity of $\mathrm{DC} / \mathrm{AC}$ inverter is $120 \mathrm{Kva}$, and the switching frequency of IGBT is $10 \mathrm{kHz}$, and filtering inductance $L=5.65 \mathrm{mH}$, and the grid, whose rated voltage is $380 \mathrm{~V}$, with $1 \mathrm{MW}$ capacity rating.

\subsection{Simulated Analysis of Switching From Mode 4 to Mode 3}

The initial operation mode of the charging station is Mode 4, and the initial conditions are as follows: $T=25^{\circ} \mathrm{C}, S=1000 \mathrm{~W} / \mathrm{m}^{2}, P_{\text {load }}=15 \mathrm{~kW}, U_{\mathrm{g}}=380 \mathrm{~V}, U_{\text {bat }}=400 \mathrm{~V}$. In times of $0.5 \mathrm{~s}$, the sunlight intensity sharply increased to $700 \mathrm{~W} / \mathrm{m}^{2}$, and the operation mode of the charging station switches from Mode 4 to Mode 3, so the station changes to off-grid. What's more, PV system only provides electricity to energy storage system and load, and no more energy was sent to the grid. $P_{\mathrm{pv}}=P_{\text {bat }}+P_{\text {load. }}$. The bi-directional DC/DC converter working in Buck mode to charge the battery storage system. The curve of public dc bus voltage is shown in Fig. 9, and Fig. 10 is the output power curve of PV and storage system.

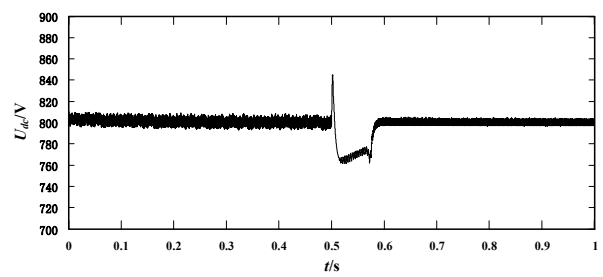

Fig.9. Public DC Bus Voltage

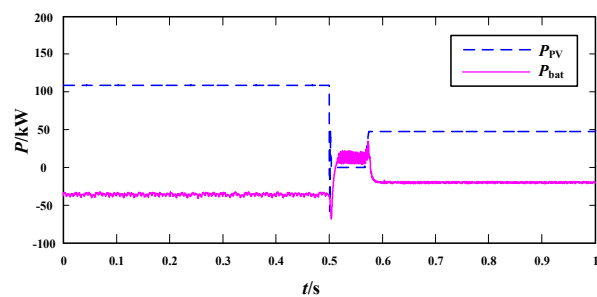

Fig.10 Output Power of PV and Storage System

As is shown in Fig. 9, the station operates rapidly stability after the operation mode switch from Mode 4 to Mode 3, and dc bus voltage is steady at $800 \mathrm{~V}$ after a slight fluctuations. After the station switch to Mode 3, the output power of energy storage is negative, namely the battery is charging as is shown in Fig. 10.

\subsection{Simulated Analysis of Switching From Mode 3 to Mode 2}

Initially, charging station works in Mode 3, and the initial conditions are as follows: $T=25^{\circ} \mathrm{C}$, $S=700 \mathrm{~W} / \mathrm{m}^{2}, P_{\text {load }}=15 \mathrm{~kW}, U_{\mathrm{bat}}=400 \mathrm{~V}$. In times of $0.5 \mathrm{~s}$, the sunlight intensity sharply decreased to 400 $\mathrm{W} / \mathrm{m}^{2}$, and the operation mode of the charging station switches from Mode 4 to Mode 3 . In addition, the output power of PV cannot meet the needs of energy storage and load, therefore the bi-directional DC/DC converter switches to Buck mode so that the battery storage system discharge electric power to reduce load power, undertaken by $\mathrm{PV}, P_{\mathrm{pv}}+P_{\text {bat }}=P_{\text {load. }}$. The curve of public dc bus voltage is shown in Fig. 11, and Fig. 12 is the output power curve of PV and storage system.

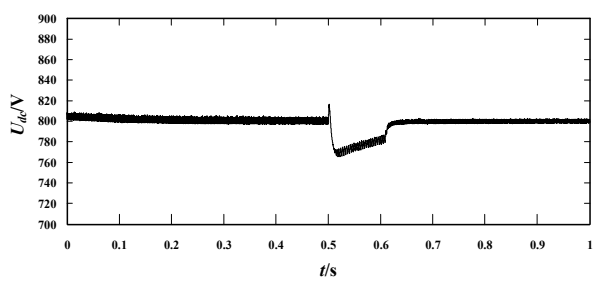

Fig.11. Public DC Bus Voltage

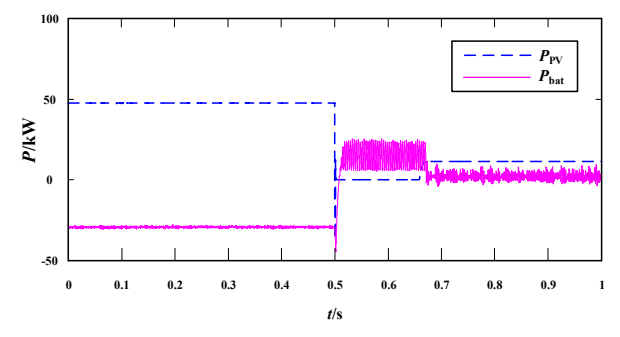

Fig.12 Output Power of PV and Storage System

Fig. 6 illustrates that the station operates rapidly stability after the operation mode switch from Mode 3 to Mode 2, and dc bus voltage, controlled by the bi-directional DC/DC converter, is steady at $800 \mathrm{~V}$ after a slight fluctuations. When station operation mode toggles to Mode 2, the energy storage 
power output is positive, in other words, the storage system and PV jointly meet the load demand as is shown in Fig. 12.

\subsection{Simulated Analysis of Switching From Mode 2 to Mode 1}

The initial operation mode of the charging station is Mode 2, and the initial conditions are as follows: $\mathrm{T}=25^{\circ} \mathrm{C}, S=400 \mathrm{~W} / \mathrm{m}^{2}, P_{\text {load }}=15 \mathrm{~kW}, U_{\mathrm{g}}=380 \mathrm{~V}, U_{\mathrm{bat}}=400 \mathrm{~V}$. In $0.5 \mathrm{~s}$ of this system operation, the sunlight intensity sharply decreased to $100 \mathrm{~W} / \mathrm{m}^{2}$, and as a result, PV array output power is almost zero, and the operation mode of the charging station switches from Mode 2 to Mode 1 . The bi-directional DC/DC converter working in Boost mode, and the storage system discharge electric power to stabilize the dc bus voltage at $800 \mathrm{~V}, P_{\mathrm{pv}}+P_{\mathrm{bat}}=P_{\text {load. }}$ The curve of public dc bus voltage is shown in Fig. 13, and Fig. 14 is the output power curve of PV and storage system.

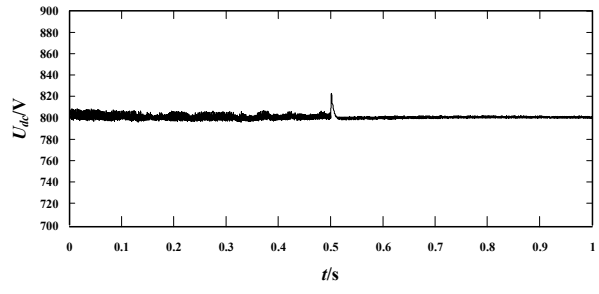

Fig.13. Public DC Bus Voltage

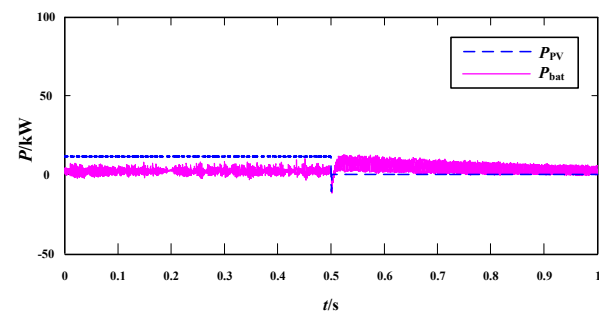

Fig.14 Output Power of PV and Storage System

As is shown in Fig. 13, the station stabilizes quickly after the operation mode switch from Mode 2 to Mode 1, and due to the effect of adjustment of the energy storage system, dc bus voltage is steady around $800 \mathrm{~V}$ after a slight fluctuations. Fig. 14 illustrates that the output power of battery storage system is positive, so that the electric power, load demand, is produced by storage system and PV collectively, $P_{\mathrm{pv}}+P_{\text {bat }}=P_{\text {load. }}$.

\subsection{Simulated Analysis of Switching From Mode 1 to Mode 4}

Initially, charging station works in Mode 1 , and the initial conditions are as follows: $T=25^{\circ} \mathrm{C}$, $S=200 \mathrm{~W} / \mathrm{m}^{2}, P_{\text {load }}=15 \mathrm{~kW}, U_{\mathrm{bat}}=400 \mathrm{~V}$. In times of $0.5 \mathrm{~s}$, the sunlight intensity sharply increased to $1000 \mathrm{~W} / \mathrm{m}^{2}$, and the output power of PV increase dramatically, so that there will be redundant power to the gird after the power needs of the load and energy storage be met, meanwhile the operation mode of the charging station switches from Mode 4 to Mode 3. The working mode of bi-directional $\mathrm{DC} / \mathrm{DC}$ converter of energy storage system is determined by DC bus voltage. When the DC bus voltage is greater than $800 \mathrm{~V}$, the converter works in Buck mode to charge the battery, and when the DC bus voltage is greater than $800 \mathrm{~V}$, the converter works in Boost mode to discharge the battery to ensure the dc bus voltage is around $800 \mathrm{~V}$. The curve of public dc bus voltage is shown in Fig. 15, and Fig. 16 is the output power curve of PV and storage system.

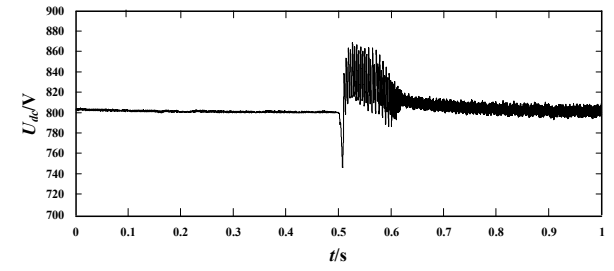

Fig.15. Public DC Bus Voltage

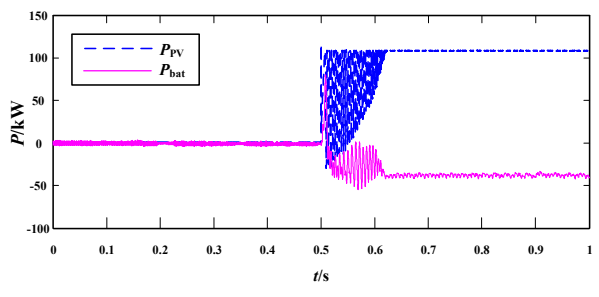

Fig.16 Output Power of PV and Storage System

Fig. 15 illustrates that when the sunlight intensity maximize the sudden changes, the station still can operate rapidly stability after the operation mode switch from Mode 1 to Mode 4, and the dc bus voltage, controlled by the bi-directional DC/DC converter, is steady at $800 \mathrm{~V}$ after a slight fluctuations. When station operation mode toggles to Mode 4, the energy storage power output is positive, $P_{\mathrm{pv}}=P_{\mathrm{bat}}+P_{\text {load, }}$ in other words, the storage system and PV jointly meet the load demand as is shown in Fig. 16. 


\section{Conclusions}

In order to make full use of photovoltaic energy, a connecting and off-grid PV charging station with storage system with high stability and good extensibility is proposed in this paper. Secondly, the control strategy of each link is introduced briefly in this work, and the grid-connected DC/AC inverter operation strategy, when the station is grid-connected or off-grid, designed in this paper was analyzed in detail. Focus on the lacking capacity with nonlinear load of the inverter when the station is grid-off, an improved double loops control method, added an output current feedback, is presented to guarantee the station running reliable during the switching between gied-connected and off-grid in this paper. Finally, we present a new energy management strategy, and the charging station operation modes are divided based on sunlight intensity. The simulation, built on Matlab platform, demonstrate the feasibility and the actual application value of the proposed scheme.

\section{References}

[1] M. Tian, Research on control strategy of distributed photovoltaic power generations with battery energy storage systems, D. Southwest Jiaotong University. 2014.

[2] G.P. Huang, X.Y. Zuo, The application of photovoltaic generation to electric automobile charging station, J. Hubei Electric Power. 36, 3(2012) 53-55.

[3] Y. Yao, G.P. Zhu, X.C. Liu, Improve of power quality of micro-grid by battery energy storage system, J. Transactions of China Electrotechnical society. 27, 1(2012) 85-89.

[4] Z.L. Yang, Y. Liu, Charging smoothness analysis of Li-ion battery charger with photovoltaic and storage energy, J. Low Voltage Apparatus. 15(2012) 31-35.

[5] S.M. Peng, Y.F. Cao, X. Cai, Control of large scale battery energy storage system interface to micro-grid, J. Automation of Electric Power Systems. 35, 16(2011) 38-43.

[6] N. Liu, X. Tang, DUAN Shuai, et.al. Capacity optimization method for PV-based battery swapping stations considering second-use of electric vehicle batteries, J. Proceedings of the CSEE. 33, 4(2013) 34-44.

[7] Y.B. Fan, C.L. Guo, Simulation study of electric vehicle chargers, J. East China Electric Power. 41, 7(2013) 1466-1470.

[8] Z. Sun, Y. Deng, X. Wang, et al, Research on steady precision of sliding mode control of a class of nonlinear systems, C. //2006 6th World Congress on Intelligent Control and Automation. IEEE. 1(2006) 1039-1043.

[9] Q.M. Cheng, G. Chen, K. Guo, et.al, Improved quasi PR droop control of charging station with PV energy storage based on SOC, J. Electric Machines and Control. 20, 2(2016).

[10] S.L. Zhou, Design and simulation research on EV charging stations with photovoltaic power, D. Hebei: Anhui University. 2010.

[11] Z.L. Yang, X.Y. Zuo, Design of photovoltaic and storage electric vehicle charging station monitoring system, J. Low Voltage Apparatus. 16(2012) 18-20.

[12] J.W. Liu, The design and implementation of energy storage device based on lithium-ion battery, D. North China Electric Power University. 2012.

[13] M. Chen, G.S. Wang, W.M. Ma, et.al, Analysis of inductor current ripple in interleaved bi-directional DC/DC power converters, J. Relay. 35, 4(2007) 53-57.

[14] G.T. Xue, Y. Zhang, D.K. Zhu, Operational control strategy of stand-alone DC micro-grid, J. Electric Power Automation Equipment. 33, 3(2013) 112-117. 
[15] L. Xu, Study on control strategies of battery energy storage system in micro-grid, D. Shandong: Shandong University. 2012.

[16] Y. Ruan, B.S. Chen, Control systems of electric drives, M. Beijing: Mechanical Industry Press. 2010. 